\title{
Design of Agricultural Ploughing Tool
}

\author{
Tejas P Phadnis*, Apoorv N Mulay, Anand S Bhujbal and Gautam J Narwade
}

Department of Mechanical Engineering, Student at MITCOE, Savitribai Phule Pune University, Pune, India

Accepted 02 March 2016, Available online 15 March 2016, Special Issue-4 (March 2016)

\begin{abstract}
In last few decades we all witnessed the development in each and every field. In the field of agricultural also we had seen remarkable development, big farmers are now a day's using cultivator, harvester, tractor, advance machine tools and advance farm equipment's, but in the country like India, 70\% of farmers are small and marginal and they are still doing farming by traditional method. Thus they are in need of improved agricultural tools that may be hand driven or bullock driven. In this paper similar advanced type of tool is designed. Modelling and analysis of Agricultural Plough is done. The input conditions are taken based on a survey leading to understanding of the zero ground conditions. Materials and manufacturing processes are selected for manufacturing the same.
\end{abstract}

Keywords: Survey, Design, Analysis

\section{Introduction}

India is agricultural country so, India's economy is mainly depends upon agriculture and agriculture based product. India's $50-60 \%$ population depends over agriculture and agriculture based industries. More than $65 \%$ farmers of India still using traditional agricultural tools. These tools are not that much efficient and well designed. They increase cost of the productivity of farm and farmer. India has been known as an agricultural country. Indian people are considered 'as a race of farmers,' and Indian life as 'essentially a country life'. Agriculture in India had developed in a remote antiquity, and down to the eighteen century India ranked among the few developed countries in globe. During the eighteen and nineteen centuries agriculture was really a vital industry of the people and with it were most closely linked all other local industries. It was on its development that the hope of raising the status of people depended. Compared with it other industries took 'a lower room'. Indian husbandman in the eighteen century had a rich stock of an agricultural techniques and implements. He used to employ a variety of instruments for husbandry purpose, some of which were introduced in England later. As per "

Anthropometric and strength data of Indian agricultural workers for equipment design", about $6.5 \%$ of the power used in crop production and related activities in the country is contributed by about 241 million workers, of which about $42 \%$ are female workers. Thus, the human workers play a major role in country. We have already known that farmers of India

*Corresponding author: Tejas P Phadnis are still using traditional tools such as Plough, Harrow, Liner, Cultivator, Seed Sowing tools. The farmers who are having land of 1 to 2 acres cannot afford a cost of cultivation, harrowing, Lining, seed sowing by the use of tractors attachments and they are facing many problems while using traditional tools including more man power requirement, problems due to faulty design, less utility, etc. Farmers which are using traditional tool system have to use different tools for different operations which are available individually. It is so time consuming and they have to pay more cost for individual tools.

\section{Objectives}

a. To observe and study the current conditions of the farmers by conducting a survey.

b. To detect and asses the severity of faults in the current ploughing tool.

c. To provide farmers with a ploughing tool which is durable and affordable and can be used in all kinds of geographical regions.

\section{Methodology}

\subsection{Problem Statement}

1) Breakage of the ploughing tool due to sudden encounter of rocks and roots present in the soil.

2) Reduction in sharpness of the ploughing tool.

3) Scope for reduction in cost of the ploughing tool.

4) Scope for increase in the life of the ploughing tool.

5) Using materials of optimum weight to increase efficiency of tool. 


\subsection{Methodology}

1. Conducting stress and displacement analysis for faulty tool by using HYPERMESH software.

2. Consider the stress and displacement analysis results by considering the maximum value of stress and displacement for all the tools.

3. Modification of the design and conducting its stress analysis.

4. Selection of optimum materials.

5. Selection of optimum manufacturing processes.

\section{Experimentation}

The experimentation consisted of conducting a survey of rural farmers from various regions. The data from the survey were arranged in tabular form. These include the crops grown by the farmers, types of failures of the tools, life of the tools, material of the tool.

Further, the results of the survey were analyzed and the problem statement of the project was finalized. The most widely used tool was identified and its dimensions were measured. Then its modelling was done and stress analysis was conducted. Thus maximum stress and maximum displacement and their locations on the tools were identified.

The loads taken were:

1) Draught force: $1200 \mathrm{~N}$

2) Vertical reaction force: $900 \mathrm{~N}$

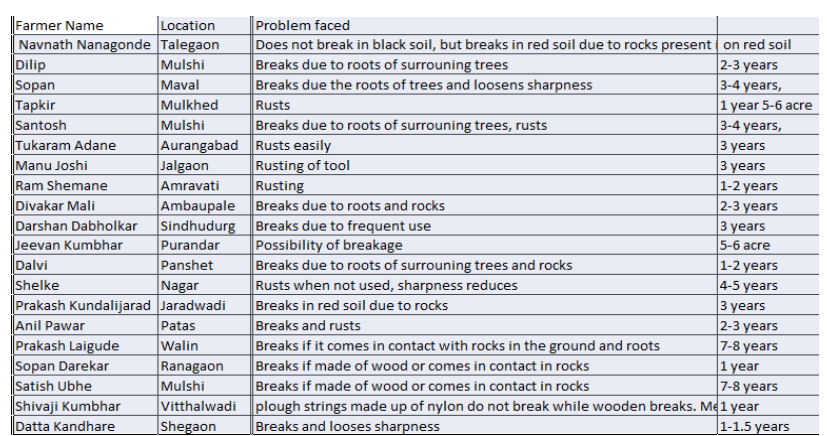

Fig.4.1 Survey of farmers

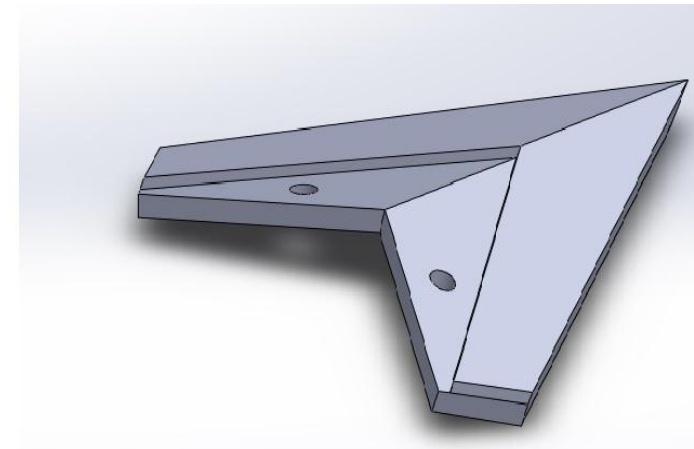

Fig 4.2 Current tool in the market

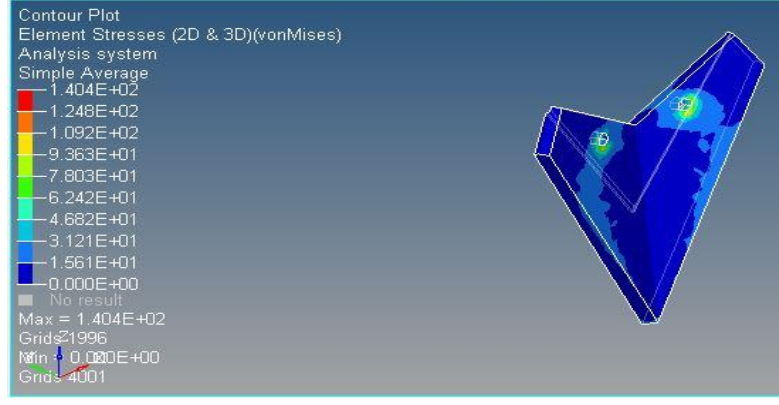

Fig 4.3 Stress Analysis of the tool

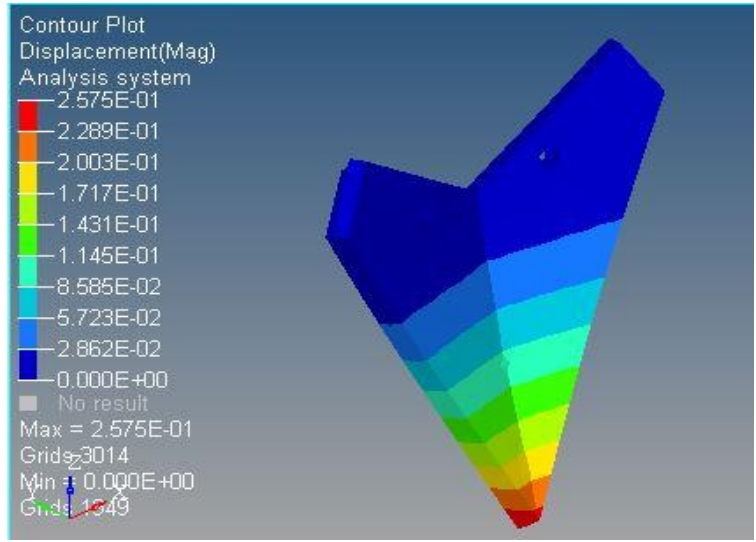

Fig 4.4 Displacement Analysis of the tool

\section{Results and Discussion}

The results obtained are divided into stress and displacement values

The maximum stress is

\section{$1.404 \mathrm{E}+02$}

The location of the stress is at the assembly of bolt hole.

The maximum displacement is

\section{$2.575 \mathrm{E}-01$}

Its location is at the tip of the tool.

The maximum stresses were occurring at the holes of the assembly of the tool and the main frame. This caused "Brittle Fracture" at the particular region.

The tip of the tool was found to be vulnerable as it was found to have maximum displacement. Thus the breakage of the tool would most probably occur at the tip. Thus the entire tool needed to be replaced due to the failure of the tip itself.

Therefore, a new method was developed of manufacturing the tool, where the tool was divided in two parts, viz. the body and the tip, and were manufactured separately. 
The requirement was to have a tough body and hard tip to prevent failure of the tool.

Therefore the material selected for the tip was "High Speed Steel"

"Grey Cast Iron" was used for the body. This also led to the reduction of maximum stress at the holes on the body.

The method used to join the two components was by means of Interference Fit (Press Fit).

Base was manufactured by casting method and the tip was manufactured by cold forging.

The stresses in the holes of the new component were greatly reduced due to our new design.

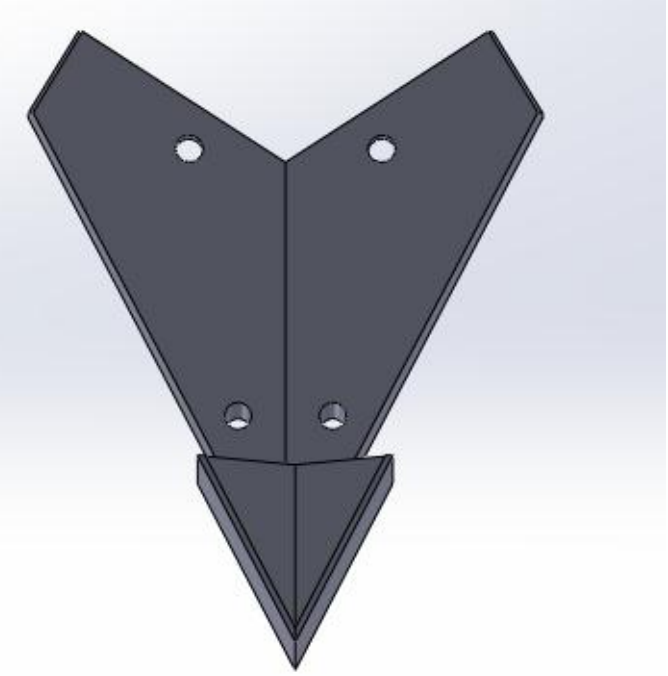

Fig 4.5 Proposed new tool

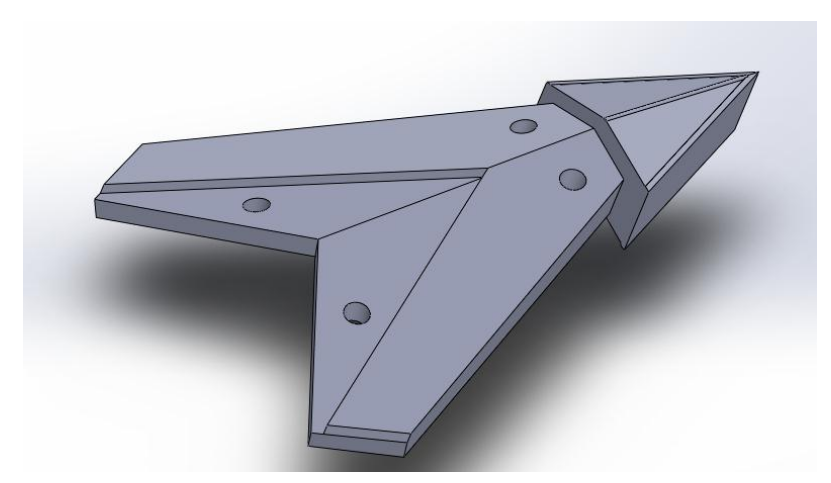

Fig 4.6 Isometric View of tool

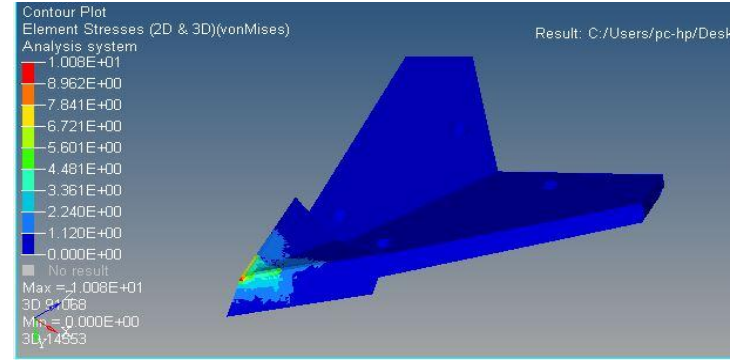

Fig 4.7 Stress analysis of new design tool

\section{Conclusion}

1) The cost of the overall tool was reduced, as, in case of failure, the farmer will only have to bear the cost of replacing the tip of the tool, and not the entire tool body.

2) The farmer receives high quality tool at low cost, as hard material is used as the tip, and its cost is less, as it has less volume.

3) The life of the tool is increased as we have to replace only the tip of the tool.

4) Frequency of breakage of tool is reduced drastically as we use very hard material for the tip of the tool. (High Speed Steel)

5) The Sharpness of the tool remains constant for a significantly longer period of time.

6) We obtain the optimum weight of the tool.

7) Efficiency and Effectiveness of the tool is increased.

8) This tip can also be used as multi-purpose tool for harvesting.

9) The holes present in the body are used for sowing purposes.

\section{Acknowledgement}

I feel happiness in forwarding this paper as an image of sincere efforts. I am very much thankful to our respected guide Prof. G. J. Narwadewho has been a constant source of inspiration. I am also thankful to MAEER's MIT College of Engineering, Pune for their constant guidance. Also I am thankful to ARAI- FID, Chakan for providing facilities for manufacturing the experimental setup.

\section{References}

S. Gebregziabhera,b,c A.M. Mouazena,d ,Design of the Ethiopian ard plough using structural analysis validated with finite element analysis.

Parvinkal Singh Mann, Navjeet Kaur Brar, Tribological aspects of agricultural equippments: A Review International Research Journal of Engineering and Technology(IRJET) e-ISSN: 23950056.

Ms. Snehal S. Wasul, Dr. A.R. Sahu2, Prof.R.D.Thakare3, Prof. U.D. Gulhane4, International Engineering Journal for Research and Development E-ISSN No: 2349-0721 Volume 2.

Daniel J. Waldorf1, Shiv G. Kapoor2, Richard E. DeVor, Mechanical and Industrial Engineering Department, University of Illinois, wW 